\title{
EFFECT OF PRESCRIBED BURNING AT DIFFERENT FUEL MOISTURE LEVELS ON GRASSLANDS IN WIND CAVE NATIONAL PARK
}

\author{
F. R. Gartner-1/ \\ E. M. White \\ L. L. Worcester
}

$1 /$ Associate Professor of Range Ecology, Professor Soil Science, and Graduate Research Assistant, respectively, South Dakota State University, Brookings.

\section{Objectives}

The study was designed to determine whether different fuel and soil moisture levels at time of ignition would alter the response of key grass species to prescribed burning.

Grasslands occupy approximately $75 \%$ of the area of Wind Cave National Park (WCNP); the remainder is dominated by ponderosa pine ( inus ponderosa), according to Lovass (1973). The Soil Conservation Service (1969) classed only about $17 \%$ of the Park area as woodland. Nearly all grassland adjacent to woodland has been invaded by ponderosa pine. Almost without exception, pine invades the little bluestem - big bluestem (Schizachyrium scorparium - Andropogon gerardi) community, but not the wheatgrass needle - grass - grama (Andropogon - Stipa - Bouteloua) community. While these two communities are frequently interspersed, the bluestem community probably occupies the largest percentage of the total grassland area.

The general relationships between fuel moisture content and fire spread (or ease of control) are well known. However, relationships between fuel and surface soil moisture content and responses of plant species to burning are not well documented. Since the key grass species of the bluestem community are major dominants throughout the Park, that community was selected for the study. Examined were the effects of three fuel moisture levels (dry, medium and wet) at ignition on postburn species composition, cover, height, weight, soil moisture and soil chemistry. The design also included an unburned (control) treatment.

\section{Methods}

A rather homogeneous bluestem community was located on Gobbler's Ridge in the southwest corner of the Park. The area, on the Park boundary, had been fenced to exclude bison and domestic livestock from neighboring ranches for about 15 years.

Two study sites were staked: the Little Bluestem site and the Mixed Grass site. The former was dominated by a nearly pure stand of little 
bluestem, while the latter was dominated by a complex of little bluestem western wheatgrass and green needlegrass with an understory similar to the Little Bluestem site.

Four replications of three fuel moisture levels (dry, medium, wet) and the unburned control were located on the Little Bluestem site and three replications of the same treatments were located on the Mixed Grass site. Treated plots on both sites were $4 \times 4 \mathrm{~m}$. Treatments were randomly assigned to plots within replicates.

Preburn data collection in spring 1978 included sampling for basal cover and culm heights of little bluestem, fuel quantity, fuel moisture, surface soil moisture, and soil chemical analyses. Postburn sampling was conducted during 1978 and 1979 growing seasons for the same parameters and for vegetation weight (yield) and soil moisture at 30,46 and $61 \mathrm{~cm}$.

To obtain a variation in fuel moisture levels within a short time period between ignition of the three treatments it was necessary to apply a measured quantity of water on the "wet" treatment. The "dry" burns were accomplished on May 26, 1978; "medium" burns on June 1 , 1978, after 0.25 to $0.50 \mathrm{in}$. of precipitation occurred the night of May 30. The "wet" burns were conducted on June 2 after the application of simulated rainfall of approximately $0.25 \mathrm{in}$.

Permanent photo points were staked at both study sites before ignition. Sequential photographs were used to complement field sampling, as well as to provide a record of phenological changes occurring after the burning treatments.

The range of pre-ignition fuel and surface soil moisture levels between treatments at Gobbler's Ridge was less than anticipated or desired (Table 1). It was concluded that dormant vegetation and mulch could be burned under wetter conditions than those occurring at the time of burning on June 1, 1978. However, because the phenological stage of development of cool season plants was so advanced, and because natural precipitation did not occur as anticipated in mid to late May, the decision was made to proceed with the burning treatments.

In order to try to obtain a wider range of pre-ignition fuel moisture conditions than existed at Gobbler's Ridge, a similar study area was located in the spring of 1979 a few miles northwest of Windy Point. The vegetation consisted of a nearly pure stand of little bluestem, similar in appearance to the Little Bluestem study site at Gobbler's Ridge. Grazing by Park ungulates had occurred, but utilization appeared to be very light.

At Windy Point two fuel moisture levels and an unburned control were incorporated in the design across four replications. Each treated area was $4 \times 4$ meters. Fuel moisture, fuel quantity, and culm heights of little bluestem were sampled immediately before ignition. Permanent photo points were staked and initial preburn photographs taken. Little bluestem culm heights and vegetation yields were sampled in July and 
August 1979.

The "wet" treatment was simulated by uniformly applying 26 gal. of water at 200 psi over a three minute period to each plot. The procedure was to apply approximately 0.25 in. of artificial precipitation in late afternoon on May 23, 1979 and burn the following morning. "Dry"' treatment plots were burned immediately after burning of the "wet" treatments was completed. All "dry" and "control" plots then received $0.25 \mathrm{in}$. artificial precipitation to preclude differential response between treatments due to application of artificial precipitation in only the "wet" burn plots.

\section{Results}

Fuel moisture levels at ignition for "dry" and "wet" burning treatments on the Little Bluestem site at Gobbler's Ridge were 30 and $46 \%$, respectively, in 1978 (Table 1). At the Windy Point location, fuel moisture levels for "dry" and "wet" burning treatments in 1979 were 27 and $54 \%$, respectively.

Results indicated that the fuel moisture levels under which the burning treatments were applied in 1978 and 1979 at both locations did not affect recovery of vegetation or total yields. At the Little Bluestem study site on Gobbler's Ridge, the weight of the cool season grass component was significantly reduced by all burning treatments in the first growing season (1978). That change was anticipated since cool season grasses (and sedges) were actively growing at the time of burning. 0ther vegetation components were not significantly affected by burning either year at any fuel moisture level,

Fuel moisture content at ignition had a significant affect on the quantity of mulch comsumed during the burns. The appearance of charred mulch and ash on the soil surface immediately after burning indicated little variation between plots within study sites. However, fuel (and presumably surface soil moisture) levels had a pronounced effect on the quantity of unburned mulch remaining on the soil surface. As fuel moisture content increased, more unburned mulch remained to serve as a protective cover over the soil. At the Little Bluestem study site, percentage fuel consumed showed a highly significant positive correlation of 0.76 to burn temperature. Fuel moisture content at ignition showed a significant negative correlation of 0.995 to burn temperature, and there was a highly significant negative correlation $(r=0.820)$ of fuel moisture to percentage of fuel consumed. Fuel moisture content could, theoretically, affect plant response if there was a long period of time between burning date and the potential of the site during a lengthy period without protective mulch over the soil surface. Furthermore, this situation could reduce infiltration of moisture into the soil profile.

Surface soil moisture at ignition had no detectable effect on postburn vegetation recovery. Soil profile moisture content did not appear to be 
related to fuel moisture conditions. However, soil moisture depletion in the first growing season after burning appeared to be related to postburn vegetation recovery rate.

Comparisons of little bluestem culm heights in the two growing seasons following burning at Gobbler's Ridge indicated a trend toward taller culms following burning. However, little bluestem culms in the unburned control treatments were almost always taller than those of the burned treatments. Differences, though small and insignificant, tended to equalize in August of the second growing season following burning.

\section{Summary}

With proper timing with regard to ease and safety of fire control, and the knowledge that fuel moisture content at ignition does not adversely affect composition or yield of vegetation, prescribed burning can become a more versatile management option.

\section{Literature Cited}

Lovass, A. L. 1973. A cooperative elk trapping program in Wind Cave National Park. Wildl. Soc. Bull. 1(2): 93-100.

U. S. Dep. Agri. 1969. Conservation plan for Wind Cave National Park. U.S.D.A., Soil Conserv. Serv., Lincoln, NE 46 pp.

\section{Acknowledgements}

The research scientists wish to express their gratitude to employees of Wind Cave National Park whose cooperation and assistance in the field made this study possible. 
Table 1. Pre-ignition surface soil moisture, fuel moisture and relative humidity at the two study sites on Gobbler's Ridge, WCNP.

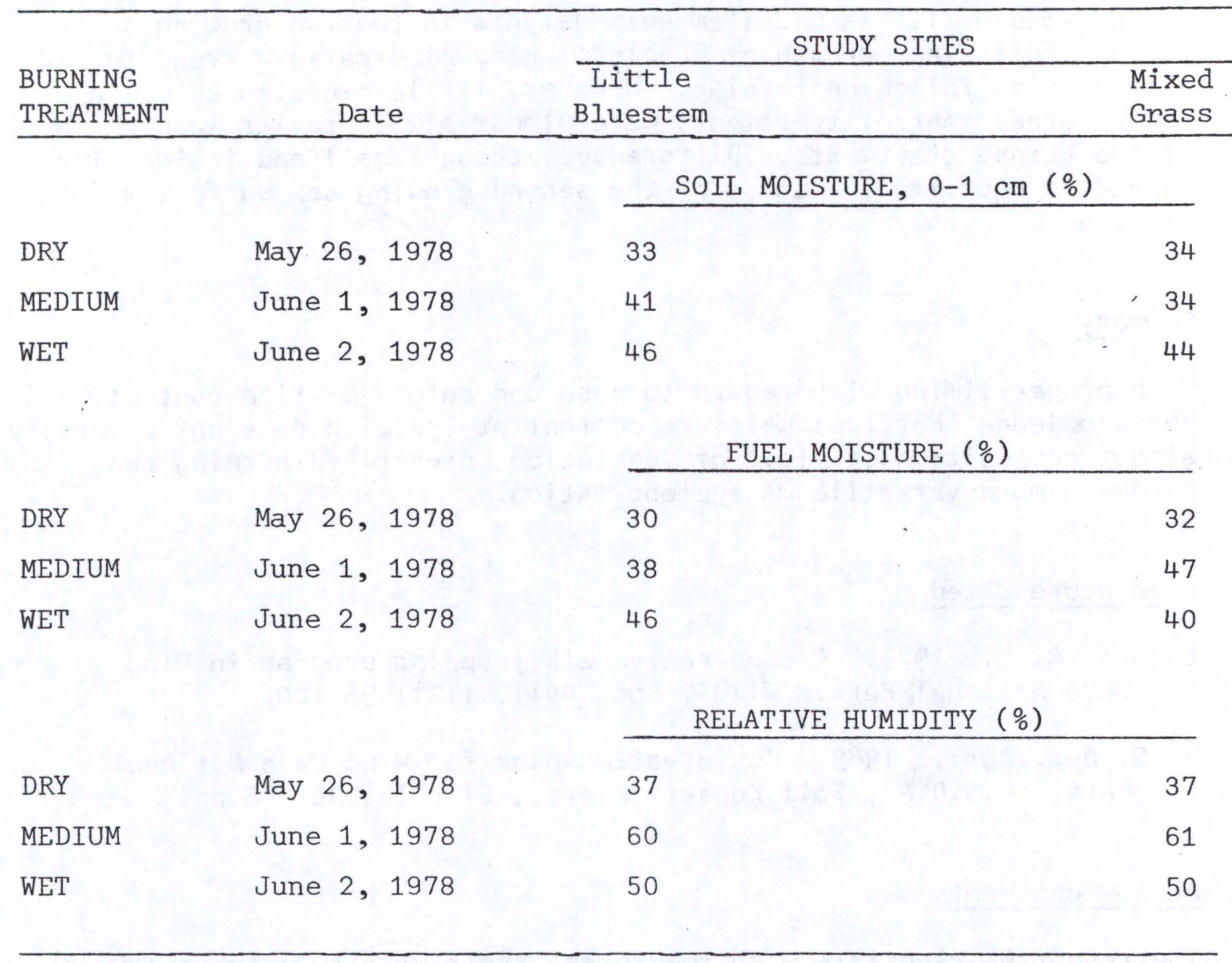

